\title{
Research on Waste Behavior of Current College Students
}

\author{
Zhao Yunchang ${ }^{1,}$, Yue Yongchao ${ }^{1,}$ a \\ 1Jilin Agricultural University, Changchun Jilin 130118 China; \\ 2 No. 156 Middle School of Changchun, Changchun Jilin 130604, China. \\ a360023251@qq.com, b 260818740 @qq.com
}

Keywords: current, students, waste behavior, investigation, research

\begin{abstract}
This article aims to investigate the waste behavior of the college students through the investigation of their daily cost, food, water, electricity and paper waste. Then the author explores the waste situation, analyzes the reason of it, and at last puts forward some solutions and countermeasures, which provides reference about strengthening the thrifty education to students for ideological and political education workers.
\end{abstract}

\section{Introduction}

In order to understand the current situation of the waste behavior of the college students, the waste behavior situation of students in Jilin Agricultural university was investigated. The research was done from the natural condition of students, their daily cost, their food waste, water waste, electricity waste and paper usage

\section{Basic information questionnaire}

40 questions were designed in the questionnaire, which involves five aspects, namely the natural situation of students (4 items), daily consumption (4 items), the food waste situation (12 items), waste water (6 items), electricity waste situation (8 items) and waste of paper (6 items)Specific investigation was done by random sampling survey manner. A total of 600 questionnaires were given out, recycling effective questionnaire 558. the recovery rate was 93\%, among which the rate of the boys accounted for $35.13 \%$, girls accounted for $35.13 \%$;urban students accounted for $41.40 \%$, rural students accounted for 58.60\%; freshman accounted for $32.80 \%$, sophomore accounted for $36.92 \%$, $25.63 \%$ for junior, and $4.66 \%$ for senior. When it came to family economic conditions, the very good condition families accounted for $7.17 \%$, good condition accounted for $20.61 \%$, general family conditions accounted for $63.98 \%$, poor condition accounted for $7.71 \%$, very poor family condition accounted for $0.54 \%$. Respondents can represent different levels of students and families, which had certain representativeness, reasonable layout. So it was worth studying.

\section{The Data Analysis of Questionnaire Survey}

Daily consumption. Students whose living cost of was 1000-1500 yuan each month occupied $33.51 \%$ of all the students, 1500 yuan and above accounted for $17.92 \%$. According to the surrounding prices around school, normal consumption level of existing school students should be less than 1000 yuan. There were only 48.57\% of the students whose consumption level was within this level, whereas the consumption level of the other $51.43 \%$ students were higher than that, which made the unnecessary consumption and waste.

The amount of students whose average monthly cost which was used in human consumption was 200-400 yuan and more than 400 yuan accounts for $38.17 \%$. In the option of "if you have a boy friend/girl friend, the costs of each semester are around which option?”, students who chose 200-500 yuan accounted for 33.51\% ,33.69\% of whom chose $500-800$ yuan, $22.94 \%$ of them chose $800-1000$ yudan, and 9.86\% chose more than 1000 yuan. The data showed that the students' monthly consumption increased to some extent, and among which the emotional investments 
accounted for a large proportion, which virtually caused waste of a certain amount of money. It also demonstrated that students have a tendency to waste, and this tendency will be made prominent gradually.

Food waste. In the dining location option survey, 32.97\% of people chose eating outside the canteen.In the "meal cost" option, 20.25\% students chose 8 to 10 yuan for each meal, students who chose more than 10 yuan accounted for $10.93 \%$. Among the surveyed students, students who bought more than three dishes every meal accounted for $8.78 \%$. When they were having dinner in the dining hall, only $30.82 \%$ chose to share their dishes. There were only $24.01 \%$ of the students who didn't waste food, while the other $75.99 \%$ of the students wasted food more or less. $30.82 \%$ of the students were indifferent to the food waste phenomenon, they even didn't have any feeling about that, and they were accustomed to that. The amount of the people who were too angry to tolerant the waste of food was only $4.84 \% .66 .13 \%$ would do nothing about the remained food; $15.05 \%$ of the people would not feel ashamed because they threw away leftover food;30.65\% thought that food waste situation was widespread.

The above data showed that consumption level of students was high, and also the waste behavior is common among them. The results suggests that many college students do not form the consciousness of saving food in their concept, which is in urgent need of research and thinking to us, and undertaking saving education to the students to pick up the traditional virtue of China. Otherwise, if waste becomes a habit of the students, the future of China will be in a mess. At the same time, it is promising that there are $93.97 \%$ of the students who want to take action to save food, which shows that students have the consciousness of saving and good foundation of thought.They could join in us as long as they will be educated and guided. They can also play a leading role in the development of the country.

Water waste. $47.85 \%$ of the respondents admitted that water waste in dormitory building is a very common phenomenon. $21.33 \%$ chose to drink "the overnight water in the cup", $31.36 \%$ used the overnight water to water the plants, and $26.52 \%$ chose to pour it into the waste water pool. This phenomenon demonstrated that college students didn't get the habit of saving water, so the phenomenon of wasting water is common among them. When the dormitory building pipe or automatic flushing system of toilet faucet box was damaged, which lead to leakage or flowing, only $36.56 \%$ students would ask for repair service timely, $27.96 \%$ would choose the specific situation to decide whether to ask for repair service or not, and $25.63 \%$ turned a blind eye to it. Based on the above result, student worker team should pay more attention to strengthen the training of the students' consciousness of saving water to protect water resources.

87.10\% students could turn off the faucet when they found the tap water was running. Students who would turn off the faucet when they apply soap while they were washing accounted for $72.04 \%$. $70.43 \%$ thought that water shortage is not far from our life. the results of the survey in the above three options factors shows that students who understood saving still occupy the mainstream. It also let us see the prospects of education of saving water.

As can be seen in the survey, the phenomenon of wasting water among college students is obvious, and waste is serious.The consciousness of saving water in urgent need of improving. Many people believed that they should enjoy it because of the payment, so the waste water conditions were serious. Society, school, parents should strengthen the propaganda of this aspect, in order to help students to enhance their understanding and so as to put into practice.

Electricity waste. Students who would take the initiative to turn off the lights after night lessons when the classroom was empty accounted for $46.77 \%$. $50.72 \%$ chose that they will turn off the lights and $2.51 \%$ choose that they will not. When the classroom was bright enough in the morning or there were ever-burning lamps in public area such as toilet, $72.94 \%$ of the students can take the initiative to turn off the lights, and $27.06 \%$ would not take the initiative to turn off the lights. Among the respondents, $69.53 \%$ of them would unplug the chargers of the mobile phone after the charging was complete, while $30.47 \%$ would not unplug the power supply in time. Among the surveyed students, $27.24 \%$ of the students could turn off the lights, cut of all of the power supply, including strip whenever they left the dormitory. $28.32 \%$ of them would not do like this sometimes, 
41.58\% would do like this after being reminded, $2.87 \%$ would never do like this. The survey showed that students not only need the education of electricity saving, but fire prevention and fire safety education was also required.

When the computer was not needed in short term ( 1 hour or so), $22.76 \%$ of the students selected normal boot of the computer, 22.58\% of them selected screen saver mode, accounted for , $42.11 \%$ would choose the standby mode. Whereas only 70 people which was accounted for $12.54 \%$ would choose to shut down the computer. Students who considered that the wast of electricity was a piece of cake because electricity is national resource, while they paid the electricity himself accounted for $19.89 \%$. $28.49 \%$ of the students felt that we were not lack of electricity, so it is not necessary to save it temporarily.

The above investigation factor is the most representative, because computer has become an inseparable part in people's daily life. Internet and mobile phones are necessary in students' life. The computer powered on has been a commonplace for a long time, which is the waste of electricity resources of the students. The ideological and political education workers in college must undertake the responsibility to educate the students about resources saving.

Paper waste. Among the respondents, $32.08 \%$ of them thought that it was not necessary to save paper, $46.42 \%$ thought that the paper waste is serious, which need improvement badly. $27.06 \%$ of the respondents considered that the waste of cleansing paper towels and disposable chopsticks were serious, $42.47 \%$ of students thought that this kind of waste is very serious, which reflected that the wood consumables such as paper waste phenomenon in current group of students is more serious which need to be addressed.

96.42\% of students would choose the back of the paper as the practicing paper.73.66\% thought that it was necessary to carry out the education of saving, environmental protection and ecological consciousness in college students. The saving awareness in college students needs to be improved. The results showed that mainstream of college students in such aspects as saving paper is good enough. So it is possible to achieve the saving, environmental protection, ecological social development goal as long as saving education is done over time.

\section{Conclusion}

Serious Waste Phenomenon among Students. Through the questionnaire survey and analysis of data processing, it is not difficult to find that waste phenomenon is serious for college students , such as money, food, water and electricity, paper, waste of resources. These aspects mainly focused on the following aspects: First, their performance for love relationship, emotional investment, hosting a party. Second, food waste after dinner. Third, electric power waste such as the ever-burning lamps, and computer being kept on; forth, paper and other resources can't be used effectively. Last,being absent from class waste many teaching and public resources to a certain extent.

Strengthening the Saving Habits of Students. As can be seen from the investigation, there are many college students who had no clear understanding about the waste and saving, they also do not have a clear attitude toward it, even some consider that it is none of their business. Good family education and school education is very important for a person's growth. However, currently, there are many students do not develop good habits and customs, so they waste a lot. Being lack of social and moral education and school management system is an important cause of the students waste of resources, which result in unstable persistence and inheritance of the traditional virtues.

Approaches for the Virtue of Saving. Society, school, especially ideological education workers should strengthen traditional virtue education of frugality, and strengthen the deep understanding of waste problem, solve the wrong understanding of students about the problem of waste, and find the root cause of waste, and the fundamental way to solve the problem. First, the students should improve the understanding of problems of waste themselves, and have their own ideas. They should make it clear that waste is not a sign of wealth, so they should not follow this trend blindly. At the same time, they should set up the correct world outlook, the outlook on life and values. They should consider the future generations. Second, school should educate the students about the saving virtue, 
strengthen the propaganda to make it by some saving activities, formulating of practical rules and regulations, which will let everybody really realize its importance. Especially the ideology education workers should strengthen the virtue education of students. Active measures should be taken to decrease the waste phenomenon. In doing so, the traditional virtues of thrift will be regained and consolidated. At last, our country should pay attention to the social moral construction to improve the citizens' moral quality fundamentally, and strengthen the ideological and moral education, which will contribute to make the students cultivate the thrift consciousness from childhood to a lifetime an action.

\section{References}

[1] Duan Ruochen, Wang Peng. Investigation and Analysis of the Phenomenon of Food Waste in College Students [J]. Journal of Ka Shi Normal College, Volume 32, 2011 (5): 85 - 87.

[2]Ma Wenyong, Wei Yaoyuan, Zhang Jianchao. Introduction to the Cultivation of the Saving Consciousness and Ability to Save of College Students [J]. Theory of Observation, 2012, (75): 191-192.

[3]Nan Chunshan. Concluding Reports on the subject of "Construction of Economical School and Saving Consciousness and Saving Ability of College Students"[J] China Education Technique and Equipment, 2011, (11) : 44-47.

[4]Wang Yang. Causes and Countermeasures of Waste Phenomenon in Contemporary College Students[J].Economic \& Trade Update, 2008,(10): 245-246.

[5]Zhao Jing. On Saving Consciousness Education of College Students [J]. Developing, 2008, (01): 95-96.

[6]Luo Yongjian, Jin Jianjun, Jiang Chong.Investigation and Analysis on Paper Waste of College Students in Beijing[J]. China Population Resources and Environment, 2010,(20): 269-272.

[7]Luo Yongjian, Yang Lingling, Wen Yuting. Investigation and Analysis of Electricity Waste Situation of Colleges Students in Beijing[J]. China Population Resources and Environment, 2009, (19): 399-403. 